\title{
Clinical Evidence of Increase in Hair Growth and Decrease in Hair Loss without Adverse Reactions Promoted by the Commercial Lotion ECOHAIR ${ }^{\circledR}$
}

\author{
María Rosario Alonso Claudia Anesini \\ Facultad de Farmacia y Bioquímica, Instituto de la Química y Metabolismo del Fármaco (IQUIMEFA), Consejo \\ Nacional de Investigaciones Científicas y Técnicas, Universidad de Buenos Aires, Buenos Aires, Argentina
}

Keywords

ECOHAIR $^{\circledR} \cdot$ Hair growth $\cdot$ Noncicatricial alopecia

\begin{abstract}
Background/Aims: Hair exerts protection, sensory functions, thermoregulation, and sexual attractiveness. Hair loss (alopecia) is caused by several diseases, drug intake, hormone imbalance, stress, and infections (Malassesia furfur). Drugs usually used in alopecia produce irreversible systemic and local side effects. An association of extracts of Coffea arabica and Larrea divaricata $\left(E C O H A I R^{\circledR}\right)$ is successfully being commercialized in Argentina for hair growth. The aim of this study was to provide scientific support for the efficacy and innocuousness of ECOHAIR ${ }^{\circledR}$ in patients with noncicatricial alopecia during a 3-month treatment. Methods: The efficacy was determined through the assessment of an increase in hair volume, improvement in hair looks, growth of new hair, and a decrease in hair loss by the test of hair count and hair traction. The capacity to decrease the amount of dandruff was also evaluated as well as the adverse local effects caused by the treatment. Results: ECOHAIR ${ }^{\circledR}$ spray improved the overall hair volume and appearance; it increased its thickness, induced hair growth, and decreased hair loss. Besides, no adverse local reactions were observed upon treatment with the product. Conclusion: This study provides scientific support for the clinical use of ECOHAIR ${ }^{\circledR}$ as a treatment to be used in noncicatricial alopecia.
\end{abstract}

(c) 2017 S. Karger AG, Basel

\section{KARGER}

(c) 2017 S. Karger AG, Basel

E-Mail karger@karger.com

www.karger.com/spp

\section{Introduction}

Hair is a protective appendage on the body that is considered an accessory structure of the integument along with sebaceous glands, sweat glands, and nails. Hair plays a role in protection, sensory functions, thermoregulation, and sexual attractiveness [1]. Both men and women suffer from hair loss and/or hair thinning. Many factors contribute to hair loss such as diseases, nutritional deficiency, aging, hormone imbalance, and infections caused by Malassesia furfur (dandruff) [2].

The hair is a complex mini-organ made up of terminally differentiated and dead keratinocytes, the matrix cells (which give rise to keratinocytes), and dermal papillae (DP), which contain fibroblasts [3] located in the deepest end of the follicle. Fibroblasts are thought to play an essential role in the induction of new hair follicles and in the maintenance of hair growth [4]. Not only are DP cells (DPCs) essential for hair follicle development through the secretion of growth factors, which stimulate the proliferation and differentiation of the follicular epithelium [5], but they are also a reservoir of cells which can differentiate into a range of therapeutically important cell types [6]. Therefore, the regulation of hair follicle regeneration depends on a complex series of paracrine interactions mediated by DPCs [7]. Moreover, DPC-derived factors have been demonstrated to influence surrounding cells, which in turn contribute to hair growth promotion [8].

Dr. Claudia Anesin 
Hair growth is a cyclical process that is divided into 3 phases: anagen (growth phase), catagen (regression phase), and telogen (resting phase) [9]. These cyclic changes involve a rapid restructuring of both epithelial and dermal components of hair follicles [10]. In fact, DPCs, mainly fibroblasts, not only regulate anagen but also catagen and telogen phases. Thus, any factor affecting the functions of DP can influence hair growth; for instance, minoxidil and epigallocatechin-3-gallate [11] stimulate hair growth by exerting antiapoptotic effects on DPCs (through an increase in the Bcl-2 [apoptosis inhibitor]/Bax ratio - an apoptosis promoter). Nevertheless, minoxidil is known to have other mechanisms of action. On the other hand, cisplatin causes hair loss through the induction of apoptosis on DPCs (through a decrease in the $\mathrm{Bcl}-2 / \mathrm{Bax}$ ratio) [12]. Moreover, reactive oxygen species can modulate the balance of the anagen/catagen phase by inducing damage of cellular DNA, proteins, and lipids which lead to cell-cycle arrest [13]. It is known that superoxide anion is involved in hair loss - interfering with nitric oxide (which is indicated as a hair growth factor). Because of that, a major role has been assigned to SOD in the control of the anagen phase and its use in alopecia by local application [14].

Alopecia is a generic term for hair loss, which results in the diminution of visible hair as a consequence of an imbalance between cell proliferation and death. The most common types are androgenetic alopecia or common baldness, telogen effluvium, chemotherapy-induced alopecia, and alopecia areata.

Nowadays, there are few drugs for the treatment of alopecia, particularly in women. In this sense, finasteride (the dihydrotestosterone-5- $\alpha$-reductase inhibitor) and minoxidil (the antihypertensive potassium channel opener) are commonly used. However, due to their limited and transient effectiveness and side effects, novel innocuous pharmacological treatments and agents are on demand.

Previously, a combination of 2 extracts of Coffea arabica and Larrea divaricata demonstrated to exert an effect on hair growth on $\mathrm{C} 3 \mathrm{H}$ mice by inducing the anagen phase [15]. Based in these results, the combination of both extracts has been registered under the name of ECOHAIR $^{\circledR}$, a trademark of Garre-Guevara laboratory. ECOHAIR $^{\circledR}$ is being successfully used in Argentina for hair recovery.

L. divaricata Cav. (Zygophyllaceae) is a plant that grows in South America, and it is widely distributed in Argentina. It is used in folk medicine for the treatment of many disorders since it has anti-inflammatory and antirheumatic properties [16]. The aqueous extract of its leaves has well-documented antitumoral and immunomodulatory activities $[17,18]$, antimicrobial properties $[19,20]$, and antioxidant activity demonstrated by peroxidase secretion of rat salivary glands [21]. Nordihydroguaiaretic acid (NDGA) has been identified as the major compound of L. divaricata leaves [22].

C. arabica belongs to the Rubiaceae family. The grains of this plant are used to prepare coffee, which is one of the most popular and widely consumed beverages worldwide due to its pleasant taste and aroma and its stimulant effect. Coffee contains several beneficial antioxidant [23] and antibacterial effects [24]. Chlorogenic acid has been identified as the major compound found in coffee extracts.

Taking into account the in vivo results in mice and the successful use of ECOHAIR ${ }^{\circledR}$ lotion, and to provide scientific support for its effect, the product was assayed in patients with noncicatricial alopecia. The primary objectives of this randomized, cohort, and prospective study were to evaluate the efficacy of treatment with ECOHAIR ${ }^{\circledR}$ spray through (1) the improvement in overall hair volume, thickness, looks, and growth and (2) the effect on hair loss. The secondary objectives were to identify possible signs of adverse local reactions related to the application of ECOHAIR ${ }^{\circledR}$ spray and to evaluate the decrease in dandruff as another signal of efficacy.

\section{Methods}

Study Design

An open, prospective, cohort (and with a unique branch phase IV) study was performed to evaluate the efficacy of ECOHAIR ${ }^{\circledR}$ spray lotion in men and women with noncicatricial alopecia during a daily administration period of 3 months in accordance with the product prospectus. The study was performed in accordance to the Comité de Ética en Investigación Clinica (CEIC; Ethical Clinical Research Committee), Ministerio de Salud de la Ciudad de Buenos Aires, under the protocol EH - 001. The study was performed at the Instituto de Hematología y Medicina Clínica Dr Rubén Dávoli, Laprida 1061 Rosario, Argentina, by Dr. Marina Rodriguez under IQUIMEFA-UBA-CONICET and LAT Research SRL guidance and supervision.

\section{Patients}

Patients were recruited during a period of 10 months (October 2013 to August 2014). Initially, the study sample comprised 72 volunteer patients. As 20 patients were withdrawn from the study due to a lack of adherence, the sample size was then reduced to 52 patients - 25 women (48.1\%) and 27 men (51.9\%). The distribution of patient ages was as follows: women had a mean age of 54.96 years (95\% CI: 49.96-60.53, median: 60, variance: 181.873, range: 30 $78)$. Men had a mean age of 41.44 years (95\% CI: 35.64-47.25, median: 39 , variance: 215.487 , range: $21-71)$. 


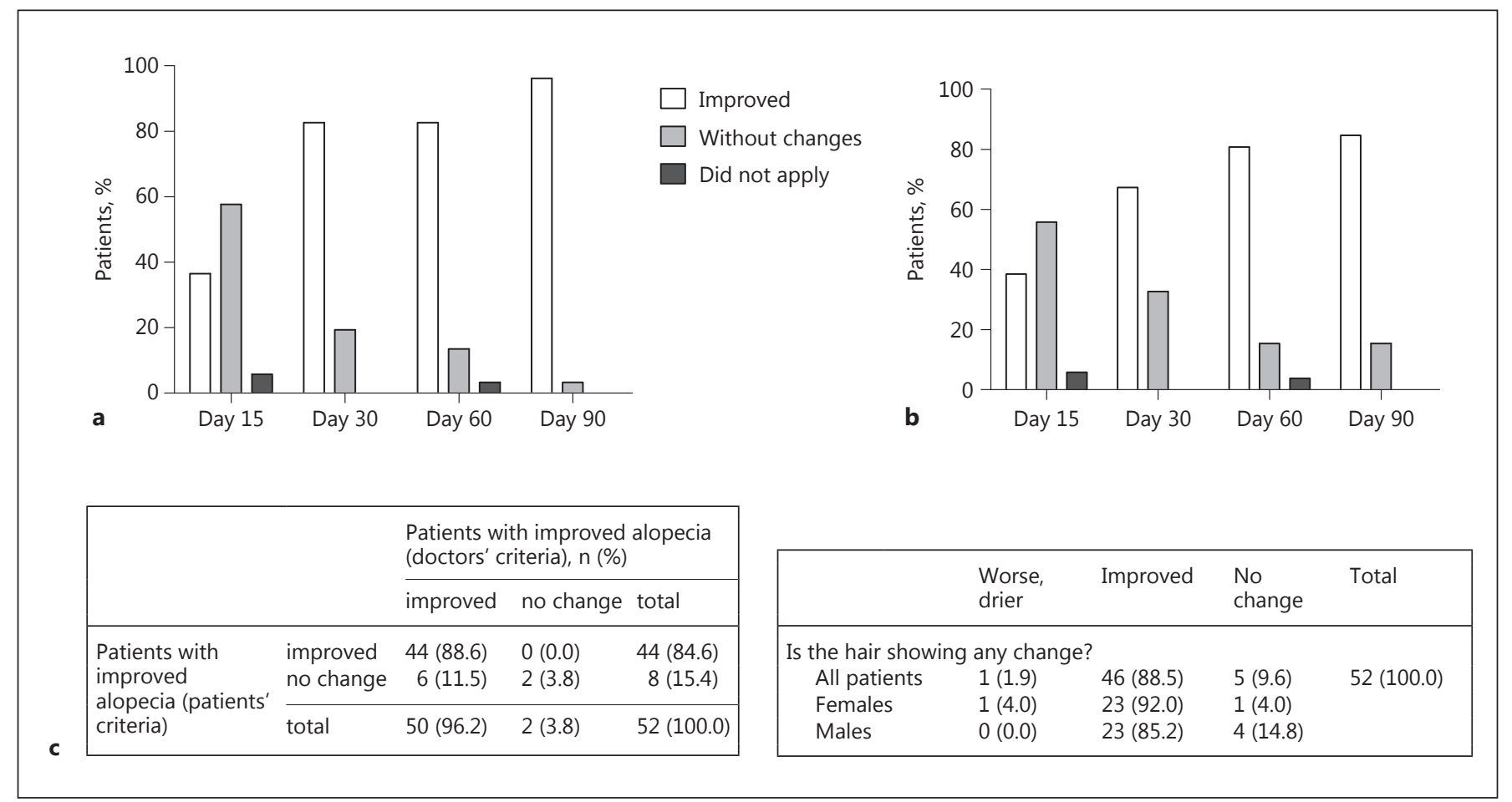

Fig. 1. Changes in alopecia assessed by doctors and patients. The graphics were constructed taking into account the percentage of patients with improved hair look during the treatment (on days 15, 30, 60, 90) according to doctors (a) and patients (b). c Table insert: statistical study of the conclusions obtained by doctors and patients on alopecia improvement and hair looks at the end of treatment. These results were obtained from questionnaires given to patients and doctors.

Before enrolling in the trial, all patients were subjected to a complete clinical revision. The following inclusion criteria were employed: (1) age older than 18 years, (2) dermatological diagnosis of noncicatricial alopecia, (3) signed informed consent form. Exclusion criteria were as follows: (1) the appearance of any acute or chronic medical condition indicative of treatment discontinuation, (2) known records of hypersensitivity to any of the excipients present in the product, (3) nonobservance of the clinical trial proceedings, (4) treatment with minoxidil or finasteride during the month previous to the clinical trial, and (5) participation in any clinical trial within a month previous to the study.

\section{Study Objectives and Assessments}

Patients were treated with ECOHAIR ${ }^{\circledR}$ spray on a daily basis, once a day, during 90 consecutive days.

Two main variables were studied: efficacy in relation to hair growth promotion, thickness, overall hair volume, the effect on hair loss, and security and tolerability. The efficacy was analyzed on days 15, 30, 60, and 90 after treatment. To this end, patients and doctors fulfilled self-assessment questionnaires about the overall volume, appearance, and thickness of hair, and signals of hair growth at different times during the treatment period.

The effect on hair growth was determined by ocular inspection employing a magnifying glass to determine the number of terminal hairs in the target area of the scalp.
To determine the effect on hair loss, patients were trained during the first visit of trial to count the hair lost after brushing for 1 min during 3 consecutive days with a fine-tooth comb. The number of fallen hairs was registered in the charts that were given to each patient. Day 15 was considered the basal value. Therefore, to calculate the decrease in hair loss, the recounting of fallen hair between days 15 and 90 was considered.

Safety measures included spontaneous reports of adverse events and any adverse events disclosed during clinical evaluations. The incidence and type of adverse local effects were registered, as well as the severity and causality accounting for a lack of adherence to the protocol. Safety data were correlated to demographic data such as age and sex, clinical information such as acute or chronic health conditions, and concomitant treatment with other drugs. The percentage of patients with adverse reactions was determined. The percentage of adverse reactions was correlated with those found in the literature, reported as frequent (1-10\%) and very frequent $(>10 \%)$.

\section{Statistical Analysis}

Several statistical tests were used: the Wilcoxon test for nonparametric median distribution of related samples, the MannWhitney $U$ test, the Kolmogorov-Smirnov test, and the median test of independent samples.

The Wilcoxon test was used to analyze the medians of counted fallen hairs on day 15 and day 90, and to analyze the medians of
Alonso/Anesini 
Table 1. Demographics and clinical characteristics of patients

a Gender distribution

\begin{tabular}{lccc}
\hline & Females $(n=52)$ & Males $(n=52)$ & Total $(n=52)$ \\
\hline $\begin{array}{l}\text { Age categories, } n \text { of patients }(\%) \\
<31\end{array}$ & $2(3.8)$ & & \\
$\quad 31-45$ & $5(9.6)$ & $6(19.2)$ & $12(23.1)$ \\
$>45$ & $18(34.6)$ & $11(21.2)$ & $11(21.2)$ \\
\hline Total & $25(48.0)$ & $27(51.9)$ & $52(100.0)$ \\
\hline
\end{tabular}

b Presence of dandruff

\begin{tabular}{|c|c|c|c|c|c|c|}
\hline & no & yes & no & yes & no & yes \\
\hline Brown & 0 & 0 & 4 & 0 & 4 & 0 \\
\hline Gray & 0 & 0 & 1 & 0 & 1 & 0 \\
\hline Black & 0 & 1 & 2 & 2 & 2 & 3 \\
\hline \multicolumn{7}{|c|}{ Normal hair } \\
\hline Brown & 10 & 0 & 7 & 1 & 17 & 1 \\
\hline Gray & 1 & 0 & 3 & 1 & 4 & 1 \\
\hline Black & 3 & 0 & 2 & 0 & 5 & 0 \\
\hline Blonde & 2 & 0 & 2 & 0 & 4 & 0 \\
\hline Gray & 0 & 0 & 0 & 0 & 0 & 0 \\
\hline Black & 2 & 0 & 1 & 0 & 3 & 0 \\
\hline Blonde & 2 & 0 & 0 & 0 & 2 & 0 \\
\hline Total & 6 & 1 & 2 & 0 & 8 & 1 \\
\hline \multicolumn{7}{|l|}{ Total } \\
\hline Brown & 12 & 1 & 12 & 1 & 24 & 2 \\
\hline Gray & 1 & 0 & 4 & 1 & 5 & 1 \\
\hline Black & 5 & 1 & 5 & 2 & 10 & 3 \\
\hline Blonde & 4 & 1 & 2 & 0 & 6 & 1 \\
\hline Total & 22 & 3 & 23 & 4 & 45 & 7 \\
\hline
\end{tabular}

c Noncicatricial alopecia subtypes

\begin{tabular}{lllll}
\hline & \multicolumn{2}{l}{ Subtypes } & & \\
\cline { 2 - 4 } & Androgenic & Areata & Telogen effluvium & Total \\
\hline $\begin{array}{l}\text { Sex, } n \text { of patients }(\%) \\
\text { Female } \\
\text { Male }\end{array}$ & $18(72.0)$ & $3(12.0)$ & $4(16.0)$ & $25(100.0)$ \\
\hline Total & $26(96.3)$ & $1(3.7)$ & $0(0.0)$ & $27(100.0)$ \\
\hline
\end{tabular}


Table 1 (continued)

d Subtypes of androgenic alopecia

\begin{tabular}{|c|c|c|c|c|c|c|}
\hline & \multicolumn{6}{|l|}{ Subtypes } \\
\hline & 1 & 2 & 3 & 4 & 5 & Total \\
\hline \multicolumn{7}{|c|}{ Sex, $n$ of patients (\%) } \\
\hline Female & $14(77.8)$ & $4(22.2)$ & - & - & - & $18(100.0)$ \\
\hline Male & $7(26.9)$ & $7(26.9)$ & $6(23.1)$ & $1(3.8)$ & $5(19.2)$ & $26(100.0)$ \\
\hline
\end{tabular}

the fallen hairs after brushing for 1 min during 3 consecutive days in women and men, and among individuals belonging to any age category.

The Mann-Whitney U test, the Kolmogorov-Smirnov test, and the median test of independent samples were used to analyze the differences between medians of counted fallen hairs of both women and men on day 90 and day 15, and among individuals belonging to any age category. $p$ values $<0.05$ were considered significant.

\section{Results}

\section{Demographics and Clinical Characteristics}

The distribution of patients according to sex and age is shown in Table 1a. Hair analysis as regards the presence or absence of dandruff and the type of hair of each patient is shown in Table $1 \mathrm{~b}$. The more frequent subtypes of noncicatricial alopecia observed in patients are shown in $\mathrm{Ta}$ ble 1c. A high percentage of women (72\%) and men (96.3\%) presented androgenic alopecia. Finally, the subtype of androgenic alopecia in women and men is shown in Table 1d. The more frequent subtypes of androgenic alopecia in women and men were types 1,2 , and 3 .

\section{Efficacy}

\section{Evaluation of Efficacy: Overall Hair Volume,}

\section{Appearance, Thickness, and Growth}

To study the efficacy of ECOHAIR ${ }^{\circledR}$ spray, patients were treated during 90 days with the spray and evaluated on days $15,30,60$, and 90. An increase in volume and thickness and an improvement in hair looks were considered changes of alopecia and analyzed by both the doctor and the patient.

When medical criteria were considered (Fig. 1a), on day 15,30 patients $(57.7 \%)$ did not show any progress, while 19 patients (36.5\%) showed some degree of improvement; 3 patients (5.8\%) were not checked. On day

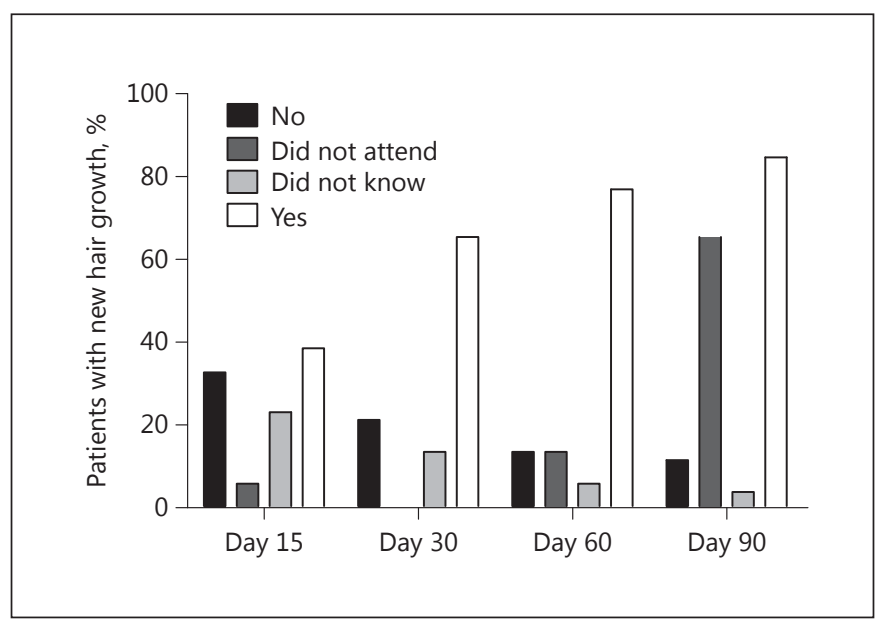

Fig. 2. Effect of the lotion on hair growth during the time of treatment. The percentage of patients that showed new terminal hair as a signal of hair growth during the treatment was determined (no: no growth observed; yes: hair growth observed).

30 , all patients were evaluated: 43 patients (82.7\%) showed improvement, and 9 patients $(17.3 \%)$ did not show any change. On day 60, 43 patients (82.7\%) improved, 7 patients $(13.5 \%)$ did not show any change, and 2 patients (3.8\%) were not evaluated. On day 90,50 patients (96.2\%) improved and 2 patients $(3.8 \%)$ did not show any improvement.

When patients' criteria were considered (Fig. 1b), on day 15, 20 patients (38.5\%) improved, and 29 patients (55.8\%) did not show any change; 3 patients $(5.8 \%)$ were not evaluated. On day 30 , all patients were evaluated: 35 patients (67.3\%) improved, and 17 patients $(32.7 \%) \mathrm{did}$ not demonstrate any change. On day 60, 42 patients $(80.8 \%)$ improved, and 8 patients (15.4\%) did not demonstrate any change; 2 patients (3.8\%) were not evaluated. On day 90,44 patients (84.6\%) improved, and 8 patients (15.4\%) did not show any improvement. 


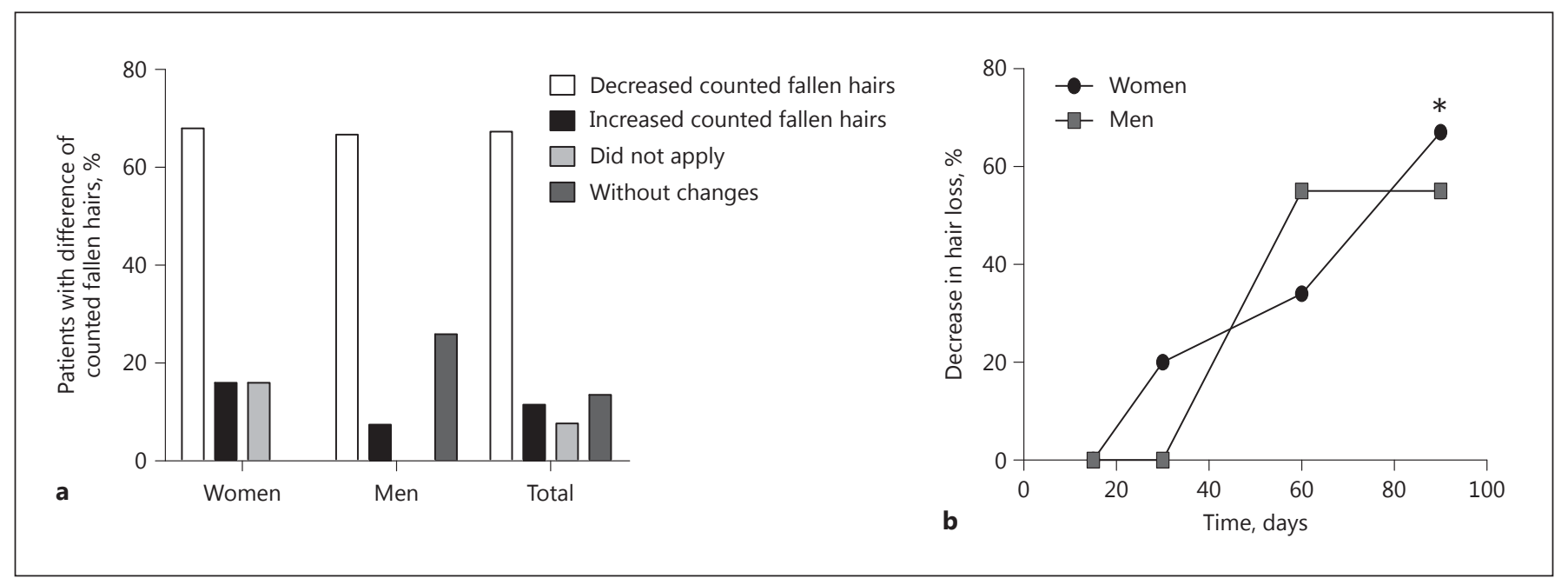

\begin{tabular}{|c|c|c|c|c|c|c|c|c|c|}
\hline Visit & & Female & Male & Total & Visit & & Female & Male & Total \\
\hline \multirow[t]{7}{*}{ Day 15} & Counted hair & & & & Day 60 & Counted hair & & & \\
\hline & Mean & 24.5 & 13.9 & 18.5 & & Mean & 17.5 & 10.2 & 13.8 \\
\hline & Median & 15.0 & 9.0 & 12.5 & & Median & 10.0 & 4.0 & 9.0 \\
\hline & Lost & 4 & 0 & 4 & & Lost & 1 & 2 & 3 \\
\hline & Maximum & 87 & 60 & 87 & & Maximum & 90 & 35 & 90 \\
\hline & Minimum & 2 & 2 & 2 & & Minimum & 1 & 2 & 1 \\
\hline & Recounting & 25 & 27 & 52 & & Recounting & 25 & 27 & 52 \\
\hline \multirow[t]{6}{*}{ Day 30} & Counted hair & & & & Day 90 & Counted hair & & & \\
\hline & Mean & 20.1 & 12.2 & 15.9 & & Mean & 13.2 & 8.1 & 10.5 \\
\hline & Median & 12.0 & 10.0 & 10.0 & & Median & 5.0 & 4.0 & 5.0 \\
\hline & Lost & 1 & 0 & 1 & & Lost & 0 & 0 & 0 \\
\hline & Maximum & 64 & 53 & 64 & & Maximum & 65 & 34 & 65 \\
\hline & Minimum & 1 & 2 & 1 & & Minimum & 2 & 2 & 2 \\
\hline & Recounting & 25 & 27 & 52 & & Recounting & 25 & 27 & 52 \\
\hline
\end{tabular}

Fig. 3. Analysis of the decrease in hair loss in relation to sex. a Percentage of men and women that showed differences of counted fallen hairs between days 15 and 90 as a signal of a decrease in hair loss during the treatment. b Decrease in hair loss (\%) in men and women during treatment. c Table insert: counted hair (mean of 3 determinants). ${ }^{*} p<0.05$, significantly different (Wilcoxon test of nonparametric median distribution of related samples).

On day 90, the conclusions obtained by doctors and patients were statistically analyzed (median test for independent samples). As can be observed in Figure 1c (table insert), patients and doctors agreed on the facts that the treatment was effective in $84.6 \%$ of patients and that there was an improvement in hair features. The null hypothesis that both agreed was affirmative $(p=$ $0.056)$.

Furthermore, the variable hair looks at the end of treatment was analyzed. For this latter analysis, sex was taken into account to find that women and men improved

ECOHAIR ${ }^{\circledR}$ Increases Hair Growth and Decreases Hair Loss in Humans their hair appearance by 92 and $85.2 \%$, respectively (Fig. 1c, table insert).

In order to determine whether ECOHAIR ${ }^{\circledR}$ induced hair growth, the number of new hairs over time was determined. To this end, an ocular inspection was done with a magnifying glass in order to determine the number of terminal hairs in the target area of the scalp. Moreover, the percentage of patients with new hairs was scored. The results of these observations are summarized in Figure 2. The number of patients with new terminal hairs increased over time, reaching $84.6 \%$ at the end of treatment. 


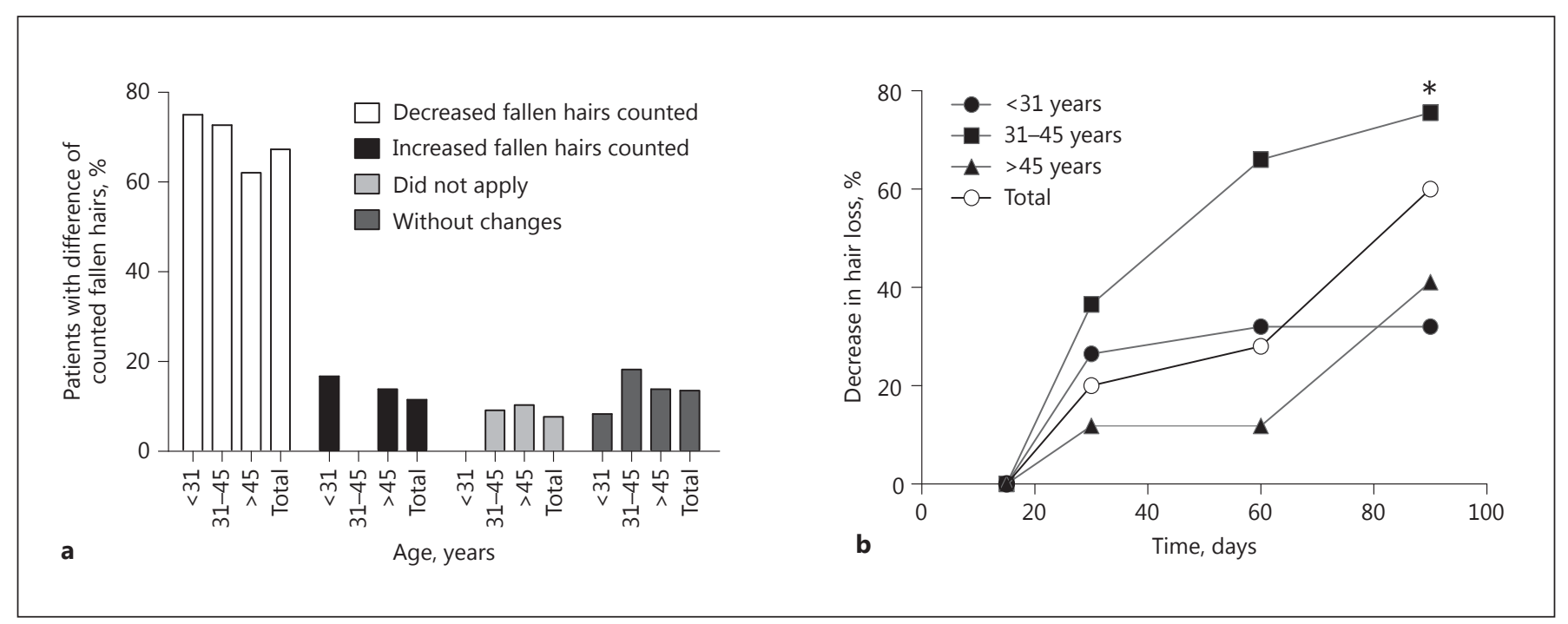

Fig. 4. Analysis of the decrease in hair loss in relation to age. a Percentage of patients $<31,31-45$, and $>45$ years that showed differences between counted fallen hairs on days 15 and 90 during the treatment. b Decrease in hair loss (\%) in patients with different range of ages during treatment. ${ }^{*} p<0.05$, significantly different (Wilcoxon test for nonparametric median distribution of related samples).

\section{Evaluation of Efficacy: Effect on Hair Loss in Relation} to Sex

The percentage of patients (women and men) who presented an increase or decrease in hair loss was studied. The percentage of patients who presented a decrease in hair loss was higher than in those who had an increase in hair loss or other categories (Fig. 3a). However, no significant differences were observed between the 2 groups analyzed.

The number of fallen hairs between day 15 and day 90 was significantly different ( $p<0.05$; Wilcoxon test for nonparametric median distribution of related samples); on day 90 the number was lower.

In order to determine whether the decrease in hair loss induced by the treatment was sex related, statistical analyses were carried out employing the Mann-Whitney $\mathrm{U}$ test, the Kolmogorov-Smirnov test, and the median test of independent samples. No differences among the group medians were observed $(p=0.061, p=0.241$, and $p=0.128$, respectively). However, when the fallen hairs, after brushing for 1 min during 3 consecutive days (see Study Objectives and Assessments), were subjected to statistical analysis, significant differences $(p<0.05$; Wilcoxon test for nonparametric median distribution of related samples) were observed in the medians of counted fallen hairs of women, who underwent a higher decrease $(21 \%)$ compared with men (Fig. 3b, c, table insert).

\section{Evaluation of Efficacy: Effect on Hair Loss in Relation} to Age

The effect of the lotion on hair loss was studied in relation to age ( $<31$ years, $31-45$ years, and $>45$ years), evaluating the parameters explained above. The percentage of patients with a decrease in hair loss was higher than the percentage of patients with an increase in hair loss between day 15 and day 90; however, no significant differences were found between age categories (Fig. 4a). It is important to note that the number of fallen hairs between day 15 and day 90 was significantly different $(p<0.05$; Wilcoxon test for nonparametric median distribution of related samples); on day 90 the number was lower.

In order to determine whether the decrease in the number of fallen hair was higher among individuals belonging to any age category, the median test of independent samples was applied. No differences among the group medians were observed ( $p=0.238)$. However, when the fallen hairs, after brushing for 1 min during 3 consecutive days (see Study Objectives and Assessments), were subjected to statistical analysis, significant differences ( $p<0.05$; Wilcoxon test for nonparametric median distribution of related samples) were observed in the medians of counted fallen hairs of the subgroup 31-45 years, showing a higher decrease in hair loss on day 90 (75\%) (Fig. 4b). 
Table 2. Effect of ECOHAIR ${ }^{\circledR}$ on dandruff

\begin{tabular}{ccll}
\hline Summary of processed data & Counted & Lost & Total \\
\hline Patients with improved dandruff, n (\%) & & \\
Patients' criteria & $7(13.5)$ & $45(85.5)$ & $52(100.0)$ \\
Doctors' criteria & $7(13.5)$ & $45(86.5)$ & $52(100.0)$
\end{tabular}

Counted: patients who presented dandruff at the beginning of the study and improved at the end. Lost: patients who did not present dandruff at the beginning of the study. Total: total number of patients in the study.

Evaluation of Efficacy: Effect on Dandruff Quantity at the End of Treatment

To determine the effect on dandruff quantity, each patient's head was subjected to ocular inspection on day 90 . As shown in Table 2, a low number of patients presented dandruff at the beginning of the study (only 7), but all of them had improved signs and symptoms at the end of the treatment.

\section{Safety and Tolerability}

Some slight adverse reactions such as burning and itching were observed only on day 15 in a few patients. The adverse reactions are presented in Table 3.

\section{Discussion}

In this study, the effect of ECOHAIR ${ }^{\circledR}$ spray on the improvement of alopecia in men and women, mainly suffering from androgenic alopecia varieties, is demonstrated. ECOHAIR ${ }^{\circledR}$ induced hair growth, improved hair appearance, decreased hair loss, and eliminated dandruff.

The stimulatory action exerted by ECOHAIR ${ }^{\circledR}$ in humans could be explained by the capacity of the 2 extracts present in the product (L. divaricata and C. arabica) to promote hair growth, as was demonstrated in mice; in this experiment the extracts were able to promote hair growth by the induction of the anagen phase [15]. In addition, the extract from $C$. arabica demonstrated a fungicidal effect in vitro on $M$. furfur, the fungus causative of dandruff and related to alopecia [25]. Taken together, these effects could provide a partial explanation for the effect of the extracts on human hair growth promotion.

The improvement in hair looks (volume and thickness) was analyzed by both patients and doctors, and the statisti-
Table 3. Adverse effects

\begin{tabular}{lc}
\hline Visits & Patients, $\mathrm{n}(\%)$ \\
\hline Day 15 & \\
No & $46(88.5)$ \\
Did not apply & $3(5.8)$ \\
Yes, slight burning & $1(1.9)$ \\
Yes, slight itching & $1(1.9)$ \\
Yes, temporal itching & $1(1.9)$ \\
Total & $52(100.0)$ \\
Day 30 & $52(100.0)$ \\
No & $52(100.0)$ \\
Total & \\
Day 60 & $50(96.2)$ \\
No & $2(3.8)$ \\
Did not apply & $52(100.0)$ \\
Total & \\
Day 90 & $52(100.0)$ \\
No & $52(100.0)$ \\
Total &
\end{tabular}

cal conclusions established that $84.6 \%$ of patients had an improvement in hair looks at the end of treatment. The latter finding could be related to the increase in hair growth demonstrated by the new terminal hairs observed and the decrease in hair loss exerted by the lotion. It is noteworthy that the effect was gradual and that a daily continuous use was required. Even though the lotion was effective in both men and women, it could be hypothesized that the sex variable had some influence in the results, as $92 \%$ of women improved their hair appearance compared with $85.2 \%$ of men. When age was considered, the lotion was efficient in all groups, but the subgroup of 31-45 years was more sensitive to the treatment. Finally, the lotion decreased the amount of dandruff, which could be related to the fact that the extract of $C$. arabica present in the lotion has an inhibitory effect on the growth of $M$. furfur [25].

Moreover, the lotion was safe, as only slight adverse reactions were observed in a few patients at the beginning of treatment. It is noteworthy that these adverse reactions did not last over time, as assessed by the dermatologist. All these results support the rational use of ECOHAIR ${ }^{\circledR}$ to promote hair growth and to prevent hair loss.

\section{Conclusions}

It can be concluded that:

- ECOHAIR ${ }^{\circledR}$ spray was demonstrated to improve hair looks in $84.6 \%$ of patients after 90 days of treatment. 
- The lotion decreased hair loss from the beginning of treatment. This effect was more marked in women. Best results were obtained in patients with androgenic alopecia subtypes 1 and 2 .

- ECOHAIR ${ }^{\circledR}$ was demonstrated to eliminate dandruff and was well tolerated.

\section{Acknowledgments}

The authors thank Laboratory Garre-Guevara s.r.l., Argentina, for the financial support for this study.

\section{Statement of Ethics}

This study was conducted in accordance with the ethical standards of the institutional and national research committee and with the 1964 Helsinki declaration and its later amendments or comparable ethical standards.
This study protocol and informed consent were reviewed and approved by an institutional review board. Informed consent was obtained from all individual participants included in the study.

This study was conducted in accordance with applicable guidelines for the protection of human subjects for research as outlined by the Comité de Ética en Investigación Clínica (CEIC) Argentina - Ministerio de Salud del Gobierno de la Ciudad de Buenos Aires (Acreditación 031 Disposición DI-2012-135-DGDOIN, Registro Nacional de Investigaciones en Salud [RENIS] Código CE000022, Office for Human Research Protection [OHRP] IRB Registration 00001678, USA).

\section{Disclosure Statement}

The authors declare no conflicts of interest.

\section{References}

1 Ebling FJ: The biology of hair. Dermatol Clin 1987;5:467-481.

2 Naito A, Sato T, Matsumoto T, Takeyama K, Yoshino T, Kato S, Ohdera M: Dihydrotestosterone inhibits murine hair growth via the androgen receptor. Br J Dermatol 2008;159: 300-305.

3 Schneider MR, Schmidt-Ullrich R, Paus R: The hair follicle as a dynamic miniorgan. Curr Biol 2009; 19:R132-R142.

4 Jahoda CA, Reynolds AJ: Induction of follicle formation and hair growth by vibrissa dermal papillae implanted into rat ear wounds: vibrissae-type fibers are specified. Development 1992;115:1103-1109.

5 Stenn KS, Paus R: Controls of hair follicle cycling. Physiol Rev 2001;81:449-494.

6 Biernaskie J, Paris M, Morozova O, Fagan BM, Marra M, Pevny L, Miller FD: SKPs derive from hair follicle precursors and exhibit properties of adult dermal stem cells. Cell Stem Cell 2009;5:610-623.

7 Robinson M, Reynolds AJ, Jahoda CA: Hair cycle stage of the mouse vibrissa follicle determines subsequent fiber growth and follicle behavior in vitro. J Invest Dermatol 1997;108: 495-500.

8 Fujie T, Katoh S, Oura H, Urano Y, Arase S: The chemotactic effect of a dermal papilla cell-derived factor on outer root sheath cells. J Dermatol Sci 2001;25:206-212.

9 Tiede S, Kloepper JE, Whiting DA, Paus R: The "follicular trochanter": an epithelial compartment of the human hair follicle bulge region in need of further characterization. Br J Dermatol 2007;157:1013-1016.
10 Paus R, Cotsareli G: The biology of hair follicles. N Engl J Med 1999;341:491- 497.

11 Kwon OS, Han JH, Yoo HG, Chung JH, Cho $\mathrm{KH}$, Kim KH: Human hair growth enhancement in vitro by green tea epigallocatechin3-gallate (EGCG). Phytomedicine 2007;14: 551-555.

12 Luanpitpong S, Nimmannit U, Chanvorachote $\mathrm{P}$, Leonard SS, Pongrakhananon V, Wang L, Rojanasakul Y: Hydroxyl radical mediates cisplatin-induced apoptosis in human hair follicle dermal papilla cells and keratinocytes through Bcl-2-dependent mechanism. Apoptosis 2011;16:769-782.

13 Hogg N: Free radicals in disease. Semin Reprod Endocrinol 1998;16:241-248.

14 Liu N, Wang LH, Guo LL, Wang GQ, Zhou XP, Jiang Y, Shang J, Murao K, Chen JW, Fu WQ, Zhang GX: Chronic restraint stress inhibits hair growth via substance P mediated by reactive oxygen species in mice. PLoS One 2013;8:e61574.

15 Davicino R, Alonso R, Anesini C: Activity of a combination of decaffeinated coffee and Larrea divaricata Cav. aqueous extract on hair growth. Patent Bull 2010;44:P090101704.

16 Ratera E, Ratera MO: Plantas de la flora Argentina empleadas en medicina popular. Buenos Aires, Hemisferio Sur, 1980.

17 Anesini C, Genaro A, Cremaschi G, Sterin Borda L, Cazaux C, Borda E: Immunomodulatory activity of Larrea divaricata Cav. Fitoterapia 1996;67:329-333.
18 Anesini C, Ferraro G, López P, Borda E: Different intracellular signals coupled to the antiproliferative action of aqueous crude extract from Larrea divaricata Cav. and nor-dihydroguaiaretic acid on a lymphoma cell line. Phytomedicine 2001;8:1-7.

19 Anesini C, Perez C: Screening of plants used in Argentine folk medicine for antimicrobial activity. J Ethnopharmacol 1993;39:119-128.

20 Stege P, Davicino R, Vega A, Casali Y, Correa S, Micalizzi B: Antimicrobial activity of aqueous extract of Larrea divaricata Cav. (jarilla) against Helicobacter pylori. Phytomedicine 2006;13:724-727.

21 Anesini C, Turner S, Borda E, Ferraro G, Coussio J: Effect of Larrea divaricata Cav. extract and nordihydroguaiaretic acid upon peroxidase secretion in rat submandibulary glands. Pharmacol Res 2004;49:441-448.

22 Walker CV, Gisvold OJ: A phytochemical investigation of Larrea divaricata Cav. J Am Pharmaceut Assoc 1945;34:78-81.

23 Ramalakshmi K, Rahath Kubra I, Jagan Mohan Rao L: Antioxidant potential of low-grade coffee beans. Food Res Int 2008;41:96-103.

24 Almeida AA, Farah A, Silva DA, Nunan EA, Gloria MB: Antibacterial activity of coffee extracts and selected coffee chemical compounds against enterobacteria. Agric Food Chem 2006;54:8738-8743.

25 Davicino R, Anesini C: Antifungal activities of aqueous extract of decaffeinated coffee against Malassezia furfur. Patent Bull 2009; 40:P080104413. 